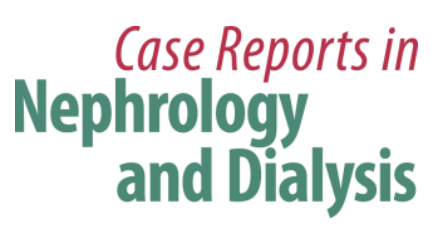

\title{
ANCA-Negative Pauci-Immune Crescentic Glomerulonephritis Linked with Non-Small Cell Carcinoma of the Lung
}

\author{
Candice Baldeo ${ }^{a} \quad$ Robert Ali $^{a} \quad$ Abdulwahab Hritani $^{\mathrm{a}} \quad$ Andreea Poenariu $^{\mathrm{b}}$ \\ Departments of ${ }^{\mathrm{a}}$ Internal Medicine and ${ }^{\mathrm{b}}$ Nephrology, University of Florida-Jacksonville, \\ Jacksonville, Fla., USA
}

\section{Key Words}

ANCA-negative pauci-immune crescentic glomerulonephritis · Non-small cell carcinoma of the lung · Interleukin- 6

\begin{abstract}
The association between malignancy and glomerular disease has been appreciated for decades [Baschinsky et al., Am J Kidney Dis 2000;36:E24]. Several types of glomerular injury in patients with cancer have been recognized [Morikawa et al., CEN Case Rep 2013;2:158-164; Baschinsky et al., Am J Kidney Dis 2000;36:E24]. The most common association is between nephrotic syndrome and carcinoma [Baschinsky et al., Am J Kidney Dis 2000;36:E24]. We report a case of anti-neutrophil cytoplasmic antibody-negative crescentic glomerulonephritis associated with lung cancer. To the best of our knowledge, only 1 other case of ANCAnegative pauci-immune crescentic glomerulonephritis associated with lung cancer has been reported [Baschinsky et al., Am J Kidney Dis 2000;36:E24].

(c) 2015 S. Karger AG, Basel
\end{abstract}

\section{Introduction}

Pauci-immune renal vasculitis with focal glomerular necrosis and crescent formation is usually associated with anti-neutrophil cytoplasmic antibodies (ANCAs). However, ANCAs are absent in up to $10 \%$ of cases, which constitutes a rarely studied variant of renal vasculitis [1]. Published data regarding kidney involvement and outcome in ANCA-negative pauciimmune vasculitis are scarce and often lack a clear-cut proof of ANCA negativity [1-3]. One of the reasons is the difficulty of establishing the absence of ANCAs.

KARGER 125:s $\quad \begin{aligned} & \text { Candice Baldeo, MD } \\ & \text { Department of Internal Medicine, University of Florida-Jacksonville } \\ & 655 \text { W 8th Street } \\ & \text { Jacksonville, FL } 32209 \text { (USA) } \\ & \text { E-Mail candice.baldeo@jax.ufl.edu }\end{aligned}$




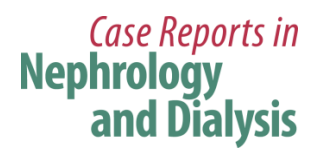

\begin{tabular}{l|l}
\hline Case Rep Nephrol Dial 2015;5:168-172 \\
\hline DOI: 10.1159/000435808 & $\begin{array}{l}\text { ○ 2015 S. Karger AG, Basel } \\
\text { www.karger.com/cnd }\end{array}$ \\
\hline
\end{tabular}

Baldeo et al.: ANCA-Negative Pauci-Immune Crescentic Glomerulonephritis Linked with Non-Small Cell Carcinoma of the Lung

Neutrophils are considered to play a major role in the pathogenesis of ANCA-negative pauci-immune crescentic glomerulonephritis (CrGN) $[1,4]$. It is possible that neutrophils and their activation by interleukin-6 (IL-6) together with several cytokines play a crucial role in the pathogenesis of ANCA-negative as well as ANCA-positive CrGN [5].

IL-6 is a pleiotropic cytokine which regulates immune responses, hematopoiesis and acute phase reactions [4]. IL-6 production by cancer cells has been demonstrated to play an important role in tumor proliferation by autocrine stimulation in some cases of lung cancer $[4,6]$. An elevated serum IL-6 level has often been found in large cell carcinoma frequently with leukocytosis and elevated levels of acute phase proteins [4]. Anti-IL-6 agents could provide a novel therapeutic strategy in patients with IL-6-producing lung cancer [5].

\section{Case Presentation}

A 69-year-old Caucasian female with a past medical history of hypertension, diabetes and atrial fibrillation was diagnosed with stage IV non-small cell lung cancer, after a lung nodule was incidentally discovered on a CT of the abdomen done for abdominal pain. She was also a chronic tobacco smoker with a 25-pack-year smoking history. Pathology from the biopsy of the right upper lobe nodule showed a moderately differentiated adenocarcinoma. A PET scan disclosed multiple, bilateral lung nodules with radiographic findings consistent with bronchoalveolar carcinoma.

She received 1 cycle of palliative chemotherapy (carboplatin/Alimta), but 2 days later, she was admitted to our institution because of severe left shoulder and chest wall pain. Serum creatinine ( $\mathrm{SCr}$ ) was normal on admission at $\mathrm{Cr}=0.57 \mathrm{mg} / \mathrm{dl}$. She had an extensive hospital stay and developed nonoliguric acute kidney injury (AKI) 1 day after a head CT with contrast was performed because she was experiencing headaches. Serum $\mathrm{Cr}$ levels elevated to $1.18 \mathrm{mg} / \mathrm{dl}$. A urinalysis showed 300 protein and large blood with 481 red blood cells. A renal ultrasound showed evidence of medical renal disease, and the spot urine protein/creatinine ratio was 11 . Serum $\mathrm{Cr}$ continued to rise with levels reaching values as high as $6.27 \mathrm{mg} / \mathrm{dl}$ with a glomerular filtration rate at $7 \mathrm{ml} / \mathrm{min} / 1.73 \mathrm{~m}^{2}$, urine sodium fractional excretion was 1.1, BUN/Cr ratio $<20$ and urine sodium $>40$. She had no recent hypotension. Albumin was $1.6 \mathrm{~g} / \mathrm{dl}$, complement C3 and C4 were negative, but the antinuclear antibody was positive (speckled, 1:80), and the rheumatoid factor was negative. A skeletal survey was also negative. Acute hepatitis panel, HIV, cryoglobulin, serum protein electrophoresis, urine immunofixation, ANCAs, double-stranded DNA, lupus anticoagulant, antihistone and antiglomerular basement membrane antibodies were all negative. A left renal biopsy showed CrGn (fig. 1) with a negative immunofluorescence and electron microscopy for immune deposits consistent with pauci-immune glomerulonephritis.

Steroids were started. Cyclophosphamide and azathioprine were also initiated with a prednisone taper. However, she developed severe neutropenia which responded to Neupogen, and therapy was switched to mycophenylate mofetil. While undergoing therapy, her urine protein/creatinine ratio improved to 0.5 ; a repeat urinalysis showed only small blood, and her serum creatinine improved to $1.9-2.8 \mathrm{mg} / \mathrm{dl}$. Unfortunately, the patient passed away about 8 months after the diagnosis of pauci-immune glomerulonephritis from a septic shock. 


\section{Case Reports in \\ Nephrology \\ and Dialysis}

\begin{tabular}{l|l}
\hline Case Rep Nephrol Dial 2015;5:168-172 \\
\hline DOI: 10.1159/000435808 & $\begin{array}{l}\text { ○ 2015 S. Karger AG, Basel } \\
\text { www.karger.com/cnd }\end{array}$ \\
\hline
\end{tabular}

Baldeo et al:: ANCA-Negative Pauci-Immune Crescentic Glomerulonephritis Linked with Non-Small Cell Carcinoma of the Lung

\section{Discussion}

CrGN is classified into 3 main categories on the basis of direct immunofluorescence microscopic observations, i.e., an anti-glomerular basement membrane $\mathrm{CrGN}$, an immune complex-mediated $\mathrm{CrGN}$, and a pauci-immune CrGN that presents as focal necrotizing glomerulonephritis with little or no glomerular staining for immunoglobulin or complement $[5,7]$.

ANCA-negative pauci-immune CrGN has been demonstrated in only a limited number of case reports [5]. The prevalence is approximately $10-30 \%[1,4]$. ANCA-negative patients also have a higher prevalence of nephrotic syndrome and poorer renal survival than ANCApositive patients [5]. However, the pathogenesis of ANCA-negative pauci-immune CrGN remains unclear [5].

Shimizu et al. [8] observed neutrophil infiltration in the glomerular lesion and elevated IL-6 and IL-8 levels in the acute phase of ANCA-negative CrGN. Morikawa et al. [5] reported a large amount of neutrophil infiltration in the glomerulus, with crescent formation, and significant elevated levels of IL- 6 , TGF- $\beta$, and IL-8 in the blood in their report of ANCA-negative pauci-immune CrGN patients associated with adenosquamous cell carcinoma of the lung. Ohlsson et al. [9] also found that plasma IL-6 levels were significantly elevated in patients with ANCA-associated vasculitis in the active phase, heralding a greater risk of relapse. In contrast to ANCA-associated vasculitis, IL-6 has rarely been reported in the pathogenesis of ANCA-negative CrGN.

Malignant tumor cells have also been reported to produce IL-6 [6]. IL-6-producing lung cancer has recently been described in several cases [5]. Yamaji et al. [6] showed that $53 \%$ of lung cancer cell lines produce IL-6 mRNA and protein with the expression level of mRNA being consistent with that of the protein.

IL-6 is a multifunctional cytokine which regulates immune responses, hematopoiesis and acute phase reactions [10]. It has been demonstrated that IL-6 plays an important role in the pathogenesis and progression of various malignancies [10]. In patients with lung cancer, IL-6 is associated with tumor proliferation and its prognosis [10]. To the best of our knowledge, only 1 previous case of ANCA-negative pauci-immune CrGN associated with lung malignancy has been reported in the literature [5].

IL-6 may play a pathogenic role with other cytokines, such as IL-8 and G-CSF, which activate neutrophils [5]. However, further clinical studies are needed to confirm the roles of IL6 in the pathogenesis of ANCA-negative pauci-immune CrGN. And thus, therapy that blocks IL-6 might be effective for vasculitis [5]. A case of ANCA-positive pauci-immune CrGN associated with metastatic adenocarcinoma of the lung has been reported, and related cases have been reviewed and analyzed [11]. However, as the serum IL-6 level was not measured, there remains the possibility that the cancer cells did not secrete IL-6, and that other cytokines other than IL-6 were associated with this clinical presentation.

\section{Disclosure Statement}

The authors declare no conflicts of interest. 
Baldeo et al.: ANCA-Negative Pauci-Immune Crescentic Glomerulonephritis Linked with Non-Small Cell Carcinoma of the Lung

\section{References}

1 Eisenberger U, Fakhouri F, Vanhille P, Beaufils H, Mahr A, Guillevin L, Lesavre P, Noël LH: ANCA-negative pauci-immune renal vasculitis: histology and outcome. Nephrol Dial Transplant 2005;20:1392-1399.

2 Hedger N, Stevens J, Drey N, Walker S, Roderick P: Incidence and outcome of pauci-immune rapidly progressive glomerulonephritis in Wessex, UK: a 10-year retrospective study. Nephrol Dial Transplant 2000;15:1593-1599.

3 Geffriaud-Ricouard C, Noel LH, Chauveau D, Houhou S, Grunfeld JP, Lesavre P: Clinical spectrum associated with ANCA of defined antigen specificities in 98 selected patients. Clin Nephrol 1993;39:125-136.

4 Chen M, Kallenberg CG, Zhao MH: ANCA-negative pauci-immune crescentic glomerulonephritis. Nat Rev Nephrol 2009;5:313-318.

5 Morikawa T, et al: AP-VAS 2012 case report: a case of ANCA-negative pauci-immune crescentic glomerulonephritis associated with IL-6-producing adenosquamous cell carcinoma of the lung. CEN Case Rep 2013;2:158-164.

6 Yamaji H, Iizasa T, Koh E, et al: Correlation between interleukin 6 production and tumor proliferation in non-small cell lung cancer. Cancer Immunol Immunother 2004;53:786-792.

7 Jennette JC: Rapidly progressive crescentic glomerulonephritis. Kidney Int 2003;63:1164-1177.

8 Shimizu M, Sekiguchi T, Kishi N, Goji A, Takahashi T, Kozan H, et al: A case of a 6-year-old girl with antineutrophil cytoplasmic autoantibody-negative pauci-immune crescentic glomerulonephritis. Clin Exp Nephrol 2011;15:596-601.

9 Ohlsson S, Wieslander J, Segelmark M: Circulating cytokine profile in antineutrophilic cytoplasmatic autoantibody-associated vasculitis: prediction of outcome? Mediators Inflamm 2004;13:275-283.

10 Higashikuni Y, Mori M, Kino H: Interleukin-6-producing giant cell carcinoma of the lung with multicentric Castleman's disease-like presentation. Intern Med 2007;46:669-673.

11 Baschinsky DY, Baker PB, Niemann TH, Wilmer WA: Pauci-immune ANCA-positive crescentic glomerulonephritis associated with metastatic adenocarcinoma of the lung. Am J Kid Dis 2000;36:E24. 


\section{Case Reports in \\ Nephrology and Dialysis}

\begin{tabular}{l|l}
\hline \multicolumn{2}{l}{ Case Rep Nephrol Dial 2015;5:168-172 } \\
\hline DOI: 10.1159/000435808 & $\begin{array}{l}\text { @ 2015 S. Karger AG, Basel } \\
\text { www.karger.com/cnd }\end{array}$ \\
\hline
\end{tabular}

Baldeo et al.: ANCA-Negative Pauci-Immune Crescentic Glomerulonephritis Linked with Non-Small Cell Carcinoma of the Lung

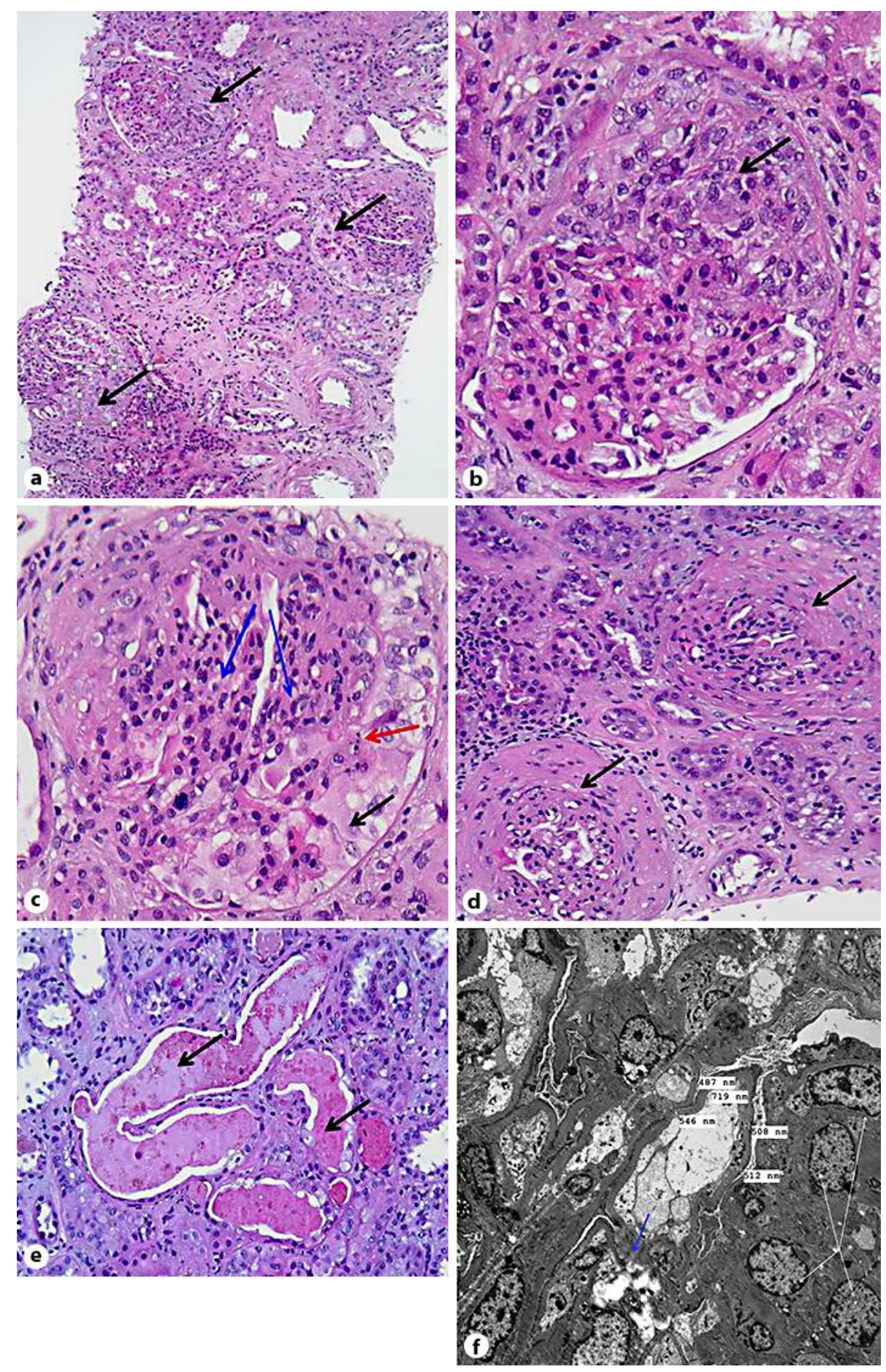

Fig. 1. a Crescents in 3 glomeruli (black arrows) in background of tubular degenerative/regenerative changes and interstitial fibrosis. b, c High-power view of cellular crescents (black arrow) with mesangial and endocapillary hypercellularity (blue arrow), nuclear fragments 'Karyorrhexis' (red arrow) and fibrin. d Fibrocellular crescents (black arrows). e Altered blood in dilated collecting ducts (black arrows). $f$ Electron microscopy showing mesangial hypercellularity (white arrows) and the focal disruption of glomerular capillary basement membranes (blue arrow) with no immune-type electron-dense deposits (HE staining. a $\times 10$, $\mathbf{b}$-e $\times 20$; electron microscopy. $\times 3,910$ ). 